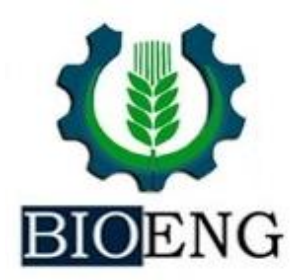

\title{
EXTRATO DE PRÓPOLIS NO CONTROLE DO Penicillium sp. E NA QUALIDADE DE SEMENTES DE COUVE-FLOR
}

\author{
E. P. de Souza' ${ }^{1}$ F. H. B. Perino²; B. S. Moscato²; P. G. N. Freitas $^{2}{ }^{*}$; S. \\ Blumer'; $^{2}$ A. I. I. Cardoso ${ }^{2}$; C. S. B. Bonini' ${ }^{1}$ A. Bonini Neto ${ }^{3}$
}

\begin{abstract}
${ }^{1}$ UNESP - Univ Estadual Paulista, Faculdade de Ciências Agrárias e Tecnológicas, Dracena, $S P$, Brasil

${ }^{2}$ FUNGE - Faculdades Gammon, Departamento de Produção Vegetal, Paraguaçu Paulista, SP, Brasil

${ }^{3}$ UNESP - Univ Estadual Paulista, Faculdade de Ciências e Engenharia, Tupã, SP, Brasil
\end{abstract}

Article history: Received 13 March 2017; Received in revised form 28 April 2017; Accepted 08 May 2017; Available online 30 June 2017.

\section{RESUMO}

Atendendo a demanda mundial por alimentos de melhor qualidade e isentos de defensivos agrícolas sintéticos, meios alternativos vêm sendo estudados para o controle de fungos. Os fungos do gênero Penicillium sp. são conhecidos como fungos de armazenamento que degradam a reserva das sementes diminuindo sua viabilidade. Diante disso, objetivou-se avaliar o efeito de soluções do extrato de própolis no controle do fungo Penicillium sp. in vitro e na qualidade fisiológica de sementes de couve-flor após o tratamento. Os tratamentos consistiram de concentrações de $0,5,10$ e $20 \%$ de extrato de própolis. O estudo foi dividido em duas etapas. Na primeira verificou-se o efeito das soluções de extrato de própolis no desenvolvimento do fungo in vitro, e na segunda a qualidade fisiológica das sementes de couve-flor tratadas. $\mathrm{O}$ delineamento experimental foi inteiramente casualizado para as duas etapas, com sete e seis repetições, respectivamente. As características avaliadas foram: crescimento micelial do fungo, e a qualidade fisiológica de sementes por meio da germinação, primeira contagem de germinação, comprimento de parte aérea e raiz de plântulas de couveflor. Solução de extrato de própolis a concentração de $20 \%$ impede o desenvolvimento do fungo Penicillium sp. in vitro e não afeta a qualidade fisiológica de sementes de couve-flor.

Palavras-chave: Brassica oleracea var botrytis; tratamento de sementes; controle alternativo.

\section{EXTRACT OF PROPOLIS IN CONTROL OF Penicillium sp. AND IN THE QUALITY OF CAULIFLOWER SEEDS}

\begin{abstract}
Supplying the world demand for better quality foods and free of agrochemicals, alternative means have been studied for the control of fungi. Fungi of the genus Penicillium sp are known as storage fungi that degrade the seed reserve and decrease its viability. Given this fact, the objective of this study was to evaluate the effect of solutions of propolis extract on the control of the fungus Penicillium sp. in vitro and in the physiological quality of cauliflower seeds after treatment. The treatments consisted of concentrations of $0,5,10$ and $20 \%$ of propolis extract. The study was divided into two stages. In the first one, the effect of propolis extract solutions on the development of the fungus in vitro was verified, and on the
\end{abstract}

*pamelanakada@dracena.unesp.br 
second the physiological quality of the treated cauliflower seeds. The experimental design was completely randomized for the two stages, with seven and six replications, respectively. The evaluated characteristics were: mycelial growth, and physiologic quality of seeds on germination, first germination count, shoot length and root of cauliflower seedlings. Concentration of $20 \%$ of the solution of propolis extract prevents the development of the fungus Penicillium sp. in vitro and does not affect the physiological quality of cauliflower seeds.

Keywords: Brassica oleracea var botrytis; seed treatment; alternative control.

\section{INTRODUÇÃO}

O Brasil é um dos maiores consumidores de defensivos agrícolas do mundo, sendo responsável pelo consumo de cerca de $50 \%$ da quantidade de defensivos utilizada na América Latina. São gastos, anualmente, cerca de 2,5 bilhões de dólares com a aquisição desses produtos (PRADO et al., 2013).

Diante dos impactos que o controle químico gera sobre o ambiente e, por conseguinte nos animais e seres humanos, a demanda por alimentos orgânicos é crescente, e com isso, os produtores adotam defensivos alternativos para $\mathrm{o}$ controle de fungos fitopatogênicos (TEQUIDA-MENESES et al., 2002; SILVA-CRUZ et al., 2015). Um dos desafios é encontrar opções para o tratamento de sementes, já que a maioria comercializada é encontrada revestida com defensivos sintéticos.

O controle cultural, controle biológico, uso de cultivares resistentes e produtos naturais com atividade indutora de resistência ou com atividade antimicrobiana compõem o manejo integrado das doenças de plantas com foco agroecológico. No caso dos produtos naturais, encontram-se os extratos vegetais com ação antimicrobiana (STANGARLIN et al., 2008). A exemplo do extrato de própolis, que de acordo com Silva et al. (2006), é uma substância resinosa colhida pelas abelhas melíferas a partir de diferentes exsudatos de plantas, como secreções de árvores, folhas e flores. Esta resina é utilizada pelas abelhas na proteção da colmeia contra a proliferação de microrganismos, incluindo fungos $\mathrm{e}$ bactérias.
Diante da composição química da própolis ser extremamente complexa, devido à grande variabilidade da flora brasileira e as condições sazonais da área, Silva et al. (2006) analisaram a própolis quanto a composição físico-química e da atividade antimicrobiana de acordo com o período de colheita das amostras, detectando teor variável de flavonoides (composto bioativo) de amostras colhidas no inverno que variou entre $0,27 \%$ e $0,38 \%$, enquanto que, no verão, teve uma variação de $0,19 \%$ a $0,52 \%$, já quanto a atividade antimicrobiana, não foi verificado efeito do extrato etanólico de própolis contra Candida albicans e Staphylococcus aureus.

Entretanto, verificando a atividade antifúngica de extratos naturais de própolis, mamona, sálvia e calêndula sobre 20 cepas de Candida albicans isoladas da cavidade bucal, Molina et al. (2008), obtiveram maior efetividade a partir do extrato glicólico de própolis verificado pela atividade antifúngica para todas as cepas de $C$. albicans testadas.

Vargas et al. (2004) avaliaram a ação antibacteriana in vitro da própolis em solução alcoólica a 50\% sobre 161 isolados bacterianos provenientes de animais, na qual o extrato de própolis inibiu $\mathrm{o}$ crescimento de $67,7 \%$ das bactérias testadas.

Também verificando o efeito in vitro, Marini et al. (2012) verificaram que o extrato alcoólico de própolis possui atividade antifúngica, embora baixa para as concentrações testadas, contra Phakopsora euvitis, Pseudocercospora vitis e Elsinoe ampelina. 
Pereira et al. (2008) verificaram o efeito antifúngico do extrato etanólico de própolis in vivo, em que o mesmo diminuiu a incidência e a severidade da cercosporiose em mudas de cafeeiro, e a incidência de ferrugem e também da cercosporiose em lavouras adultas nesta mesma cultura, observado nos dois casos redução linear na incidência da doença com o aumento das concentrações do extrato na calda de pulverização.

Quanto a utilização da própolis sobre a inibição de patógenos que acometem o tegumento de sementes, Vieira et al.(2010) trataram sementes de feijão com soluções de extrato de própolis e detectaram eficiência no controle de vários fungos.

Um dos fungos de deterioração de sementes são os do gênero Penicillium sp., atacam ampla gama de espécies vegetais, inclusive as reservas de sementes, com isto

\section{MATERIAL E MÉTODOS}

$\mathrm{O}$ experimento foi realizado em duas etapas, sendo a primeira no Laboratório de Microbiologia e a segunda no Laboratório de Sementes da Faculdade Gammon, localizada em Paraguaçu Paulista-SP, no período de agosto de 2014 a março de 2015.

$\mathrm{Na}$ primeira etapa foi estudado soluções de extrato de própolis no controle do fungo Penicillium sp. in vitro. $\mathrm{O}$ fungo foi isolado de um fruto de mexerica (Citrus deliciosa) em placas de petri com meio de cultura BDA (Batata, Dextrose, Agar: mistura de 39 gramas de BDA para um litro de água autoclavado a $121^{\circ} \mathrm{C}$ por 15 minutos), permanecendo por sete dias sob temperatura ambiente aproximada de $25^{\circ} \mathrm{C}$ e fotoperíodo de 12 horas de luz para desenvolvimento do fungo.

Os tratamentos consistiram de soluções de extrato de própolis nas concentrações de $0,5,10$ e $20 \%$ do produto Propomax ${ }^{\circledR}$ que foram incorporados ao meio BDA (BatataDextrose-Ágar) mantendo-se estas concentrações, e vertido em placas de Petri. O isolado do fungo foi inoculado nestas placas, as quais permaneceram por reduzindo o vigor, logo sua qualidade fisiológica. Em sementes de couve-flor não é diferente, ele se instala externamente por meio de seus esporos, germinam e infectam internamente causando sérios prejuízos, consumindo as reservas do eixo embrionário e consequentemente reduzindo a longevidade dessas sementes. Diante de toda exposição de trabalhos demonstrando o efeito antifúngico do extrato de própolis, ainda não foi observado seu uso neste tipo de sementes, portanto, não se sabe o efeito sobre a germinação e vigor em sementes de couveflor.

Diante deste cenário, objetivou-se com este trabalho avaliar o efeito de soluções do extrato de própolis no controle do fungo Penicillium sp. in vitro, e na qualidade fisiológica de sementes de couve-flor após o tratamento.

sete dias sob temperatura ambiente a $25^{\circ} \mathrm{C}$ e fotoperíodo de 12 horas de luz para desenvolvimento do fungo. Após esse período, foi medido o crescimento micelial do fungo com auxílio de uma régua, expresso em centímetros.

$\mathrm{Na}$ segunda etapa foi feito o tratamento de sementes de couve-flor da cultivar Bola de Neve com as mesmas concentrações citadas anteriormente com extrato de própolis.

As sementes foram tratadas, agitando-se por cinco minutos (ASSIS et al., 2012), com as mesmas concentrações do extrato de própolis. Retirou-se o excesso da solução, e em seguida foram colocadas sobre papel toalha permanecendo em câmara fria por 24 horas para secagem.

As características avaliadas foram: germinação e vigor (primeira contagem de germinação e comprimento da parte aérea e raiz). Para o teste de germinação foram semeadas 50 sementes em caixas gerbox com dois papéis mata-borrão sendo umedecido com água destilada (2,5 vezes o peso do papel em mililitros). Estas permaneceram em germinador sob 
temperatura constante de $20^{\circ} \mathrm{C}$ (BRASIL, 2009). A primeira contagem de germinação foi realizada ao quinto dia após a semeadura, contabilizando as plântulas normais, expresso em porcentagem. Ao décimo dia realizou-se a segunda contagem de germinação contabilizando-se plântulas normais e anormais, expresso em porcentagem (BRASIL, 2009). Para avaliação do comprimento de parte aérea e raiz, foram amostradas 10 plântulas normais do teste de germinação medidas com auxílio de

\section{RESULTADOS E DISCUSSÃO}

$\mathrm{Na}$ primeira etapa do experimento, que foi a exposição do fungo sobre o meio BDA juntamente com as soluções do extrato de própolis, houve diferença quanto ao crescimento micelial do fungo (Figura 1). Assim foi ajustada a regressão linear, e quanto maior a concentração de própolis, menor foi o crescimento micelial, e na concentração de $20 \%$ não houve desenvolvimento do fungo. O provável motivo é a concentração de flavonoides contida na própolis, que tem efeito régua, expresso em centímetros (GUEDES et al., 2013).

Nas duas etapas do estudo o delineamento experimental adotado foi inteiramente casualizado com sete e seis repetições, primeira e segunda etapa, respectivamente.

Os dados foram submetidos à análise de variância pelo teste $\mathrm{F}$ à $5 \%$ de probabilidade, as médias foram ajustada através da análise de regressão, ao mesmo nível de probabilidade. antimicrobiano (LONGHINI, 2007). Vieira et al. (2010) ao testarem extrato de própolis sobre alguns fungos fitopatogênicos em sementes de feijão, como Alternaria spp., Aspergilus spp, Cladosporium spp., Coletotrichum spp., Alternaria spp., Dendrophoma spp. e Fusarium spp., também detectaram efeito na redução de crescimento destes fungos, tratando-as sob agitação por 30 e $60 \mathrm{~min}$, tempo este bem superior ao utilizado no presente experimento.



Figura 1. Crescimento micelial do fungo Penicillium sp. desenvolvido in vitro em função de diferentes soluções de extrato de própolis. Paraguaçu Paulista, 2014.

Marini et al. (2012) testaram a fungitoxicidade de extratos alcoólicos de própolis sobre o crescimento micelial e esporulação, no qual utilizaram as concentrações de 0,$05 ; 0,1 ; 0,2 ; 0,4 ; 0,5$ e $1 \%$ do extrato, e os autores concluíram que o extrato possui atividade antifúngica in vitro, embora baixa para as concentrações testadas, contra Phakopsora euvitis, Pseudocercospora vitis e Elsinoe ampelina. Já Machado et al. (2015) ao testarem as concentrações de $0,4,8,16,32$ 
e $64 \mathrm{~mL} \mathrm{~L}^{-1}$ de extrato etanólico de própolis em Lasiodiplodia theobromae e Colletotrichum gloesporioides, principais patógenos que acometem os frutos da manga, não detectaram controle sobre o crescimento micelial dos fungos após período de 96 horas.

Em aplicação de extrato etanólico de própolis contra a cercosporiose e a ferrugem em cafeeiros, Pereira et al. (2008) detectaram efetividade quanto ao uso do extrato, e que este efeito pode ter sido causado por três hipóteses. A primeira se baseia na formação de uma camada protetora que a cera da própolis gera sobre as folhas, impedindo a germinação e penetração do fungo ao tornar a superfície da folha hidrofóbica. A segunda hipótese seria a presença de algum nutriente contido na própolis que aumentasse a resistência das folhas. E a última, e mais provável hipótese, é de que a própolis atue como um elicitor de resistência, propiciando resistência às plantas, por promover incremento no metabolismo de fenois.

Pereira et al. (2013) ao aplicarem concentrações de $0 ; 0,5 ; 1,0 ; 1,5 ; 2,0$ e $2,5 \%$ de extrato etanólico de própolis em mudas de café contra a cercosporiose, concluíram que 1,$0 ; 1,5$ e $2,0 \%$ do extrato proporcionaram menor incidência da doença. Resultados semelhantes ocorreram na pesquisa de Vieira et al. (2009). Os autores testaram duas concentrações de extrato de própolis $(0,8$ e $1,6 \%)$ pulverizando em plantas de pepino para controle do oídio (Sphaerotheca fuliginea), concluindo atividade antifúngica na maior dose.

Pulverizações de extrato de própolis na concentração de $10 \%$ foi aplicado em tomateiro com intuito de controlar oídio após o aparecimento dos primeiros sintomas, e os pesquisadores detectaram alta efetividade da própolis, a qual não diferiu do fungicida sistêmico (tebuconazole) (MORAES et al., 2011).

Vale destacar que não é possível a comparação fiel dos resultados deste estudo com as referências utilizadas na discussão deste artigo, embora em alguns casos as soluções são semelhantes, por outro lado há variação na composição comercial de cada produto, e os trabalhos citados não mencionaram o nome comercial do produto, como também não confirmaram se a solução era elaborada com o puro ingrediente ativo (própolis).

$\mathrm{Na}$ segunda etapa do trabalho, que foi a aplicação das soluções do extrato de própolis no tratamento de sementes de couve-flor, não houve diferença entre os tratamentos quanto à qualidade fisiológica das sementes: primeira contagem de germinação, porcentagem de germinação, plântulas anormais, comprimento de parte aérea e raiz (Tabela 1). Estudo realizado por Vieira et al. (2010) também não houve interferência no efeito sobre a qualidade fisiológica de sementes de feijão, quando submetidas em soluções de extrato de própolis nas concentrações de 2, 4, 8 e 16 $\mathrm{mL} \mathrm{L}{ }^{-1}$, que se mantiveram sob agitação por tempo de 30 e $60 \mathrm{~min}$.

Havia-se a preocupação de que as concentrações de estudo poderiam afetar o embrião das sementes, e assim resultando em não emissão e emergência das plântulas normais, devido o relato em estudo de King-Días et al. (2015). Estes autores verificaram que os flavonoides interferem com o fluxo de elétrons na reação de Hill (fotólise da água) e assim afetando desenvolvimento de plantas. Além deste efeito em reações metabólitas, esperava-se que estas concentrações poderiam dessecar o eixo embrionário, o que não aconteceu. 
Tabela 1. Média para primeira contagem de germinação (PCG), germinação (G), plântulas anormais, comprimento de parte aérea (CPA) e raiz (CR) em função do tratamento de sementes de couve flor em soluções de extrato de própolis. Paraguaçu Paulista, 2014.

\begin{tabular}{cccccc}
\hline Dose & $\begin{array}{c}\text { PCG }^{*} \\
(\%)\end{array}$ & $\begin{array}{c}\mathrm{G}^{*} \\
(\%)\end{array}$ & $\begin{array}{c}\text { Anormais* } \\
(\%)\end{array}$ & $\begin{array}{c}\text { CPA } \\
(\mathrm{cm})\end{array}$ & $\begin{array}{c}\mathrm{CR}^{*} \\
(\mathrm{~cm})\end{array}$ \\
\hline 0 & 83 & 85 & 12 & 5,2 & 5,1 \\
\hline 5 & 82 & 87 & 11 & 5,5 & 5,1 \\
\hline 10 & 82 & 88 & 9 & 5,3 & 4,5 \\
\hline 20 & 82 & 83 & 14 & 5,2 & 5,2 \\
\hline Média & 82 & 86 & 12 & 5,3 & 4,9 \\
\hline $\mathrm{CV}(\%)^{* *}$ & 8,2 & 8,0 & 44,5 & 5,2 & 10,5 \\
\hline
\end{tabular}

*Não significativo a $5 \%$ de probabilidade.

**Coeficiente de variação.

Nota-se a eficiência da própolis na inibição de desenvolvimento de diversos microrganismos fúngicos, inclusive como consta na Figura 1, e diante dos fatos,

\section{CONCLUSÃO}

Solução de extrato de própolis na concentração de $20 \%$ impede o desenvolvimento do fungo Penicillium sp.

\section{REFERÊNCIAS}

ASSIS, M.O.; RODRIGUES, B.R.A.; DAVID, A.M.S.S.; CANGUSSÚ, L.V.S.; MOTA W.F. Potencial fisiológico de sementes de coentro e resposta ao tratamento com fertilizante à base de zinco e molibdênio. Horticultura Brasileira v.30, S7867-S7874. 2012.

BRASIL. Ministério da Agricultura, Pecuária e Abastecimento. Regras para análise de sementes. Brasília: Mapa/ACS, 2009. 399p.

SILVA-CRUZ, M. E., FREITAS SCHWAN-ESTRADA, K. R., BALBIPEÑA, M. I., TERUMI ITAKO, A., CLEMENTE, E., STANGARLIN, J. R. (2015). Control del moho azul en poscosecha de manzana con productos naturales. Idesia (Arica), v. 33, n. 2, 57-63.

GUEDES, R.S.; ALVES, E.U.; COSTA, E.M.T.; SANTOS-MOURA, S.S.; SILVA, R.S.; LONGHINI, R.; RAKSA, S. M.; OLIVEIRA, A. C. P.; SVIDZINSKI, T. I. E., FRANCO, S. L. Obtenção de extratos destaca-se um promissor método alternativo para o setor de produtos orgânicos, o que ainda é ausente para o tratamento de sementes neste fim.

in vitro, e não afeta a qualidade fisiológica de sementes de couve flor.

de própolis sob diferentes condições e avaliação de sua atividade antifúngica. Revista Brasileira Farmacogn, v. 17, n. 3, 2007. Disponível em: <http://www.scielo.br/pdf/rbfar/v17n3/14. pdf>. Acesso em: 27 nov. 2016.

B. KING-DÍAZ, J. GRANADOSPINEDA, M. BAH, J.F. RIVERO-CRUZ, B. LOTINA-HENNSEN. Mexican propolis flavonoids affect photosynthesis and seedling growth. Journal of Photochemistry and Photobiology B: Biology, v. 151, p. 213-220, 2015.

MACHADO, P. P.; VIEIRA, G. H. C.; MACHADO, R. A. Uso da própolis e óleo de nim no controle dos fungos Lasiodiplodia theobromae e Colletotrichum gloesporioides: principais patógenos que acometem os frutos da manga. Revista de Agricultura Neotropical, Cassilândia-MS, v. 2, n. 4, p.31-37, 2015. 
MARINI, D.; MENSCH, R.; FREIBERGER, M.B.; DARTORA, J.; FRANZENER， G.; GARCIA， R.C.; STANGARLIN, J.R. Efeito antifúngico de extratos alcoólicos de própolis sobre patógenos da videira. Arq. Inst. Biol., São Paulo, v.79, n.2, p.305-308, 2012.

MOLINA, F.P.; MAJEWSKI, M.; PERRELA, F.A.; OLIVEIRA, L.D.; JUNQUEIRA, J.C.; JORGE, A.O.C. Própolis, sálvia, calêndula e mamona atividade antifúngica de extratos naturais sobre cepas de Candida albicans. Ciência Odontológica Brasileira, v. 11, n.2, p. 8693, 2008.

MORAES, W. B.; JESUS JUNIOR, W. C.; BELAN, L. L.; PEIXOTO, L. A.; PEREIRA, A. J. Aplicação foliar de fungicidas e produtos alternativos reduz a severidade do oídio do tomateiro. Revista Nucleus, v. 8, n. 2, p.57-68, 2011.

PEREIRA, C.S.; GUIMARÃES, R.J.; POZZA, E.A.; SILVA, A.A. Controle da cercosporiose e da ferrugem do cafeeiro com extrato etanólico de própolis. Revista Ceres, v. 55, n.5, p, 369-376, 2008.

PEREIRA, C. S.; SOUZA, F. L. F.; GODOY, C. A. Extrato etanólico de própolis no controle da cercosporiose e no desenvolvimento de mudas de cafeeiro. Revista Brasileira de Agroecologia, v. 8, n.1, p. 170-178, 2013.

PRADO, A.L.; FONSECA, M.C.M.; GONÇALVES, M.G.; LEHNER, M.S.; PAULA-JÚNIOR, T.J.; SILVA, A.F. Atividade antifúngica de óleos essenciais e extratos vegetais sobre fungos fitopatogênicos. Seminário de Iniciação Científica e Tecnológica, Belo Horizonte, 10., 2013. Disponível em: <http://www.epamig.br/index.php?option= com_docman\&task $=$ doc

download\&gid=2991> Acesso em: $04 \mathrm{dez}$. 2016.

SILVA, R.A.; RODRIGUES, A.E.; RIBEIRO, M.C.M.; CUSTÓDIO, A.R.; ANDRADE, N.E.D.; PEREIRA, W.E. Características físico-químicas e atividade antimicrobiana de extratos de própolis da
Paraíba, Brasil. Ciência Rural, Santa Maria, v.36, n.6, p.1842-1848, nov-dez, 2006.

STANGARLIN， J.R.; KUHN， O.J.; SCHWAN-ESTRADA, K.R.F. Controle de doenças de plantas por extratos de origem vegetal. Revisão Anual de Patologia de Plantas, v.16, p.265-304, 2008.

TEQUIDA-MENESES, M., CORTEZROCHA, M., ROSAS-BURGOS, C., LOPEZ-SANDOVAL, S., CORRALESMALDONADO, C. Efecto de extractos alcoholicos de plantas silvestres sobre la inhibición de crecimiento de Aspergillus flavans, Aspergillus niger, Penicilliun expansum, Fusarium moniliforme $y$ Fusarium poae. Revista Iberoamericana de Micología, v. 19, p. 84-88, 2002.

VARGAS, A.C.; LOGUERCIO, A.P.; WITT, N.M.; COSTA, M.M.; SILVA, M.S.; VIANA, L.R. Atividade antimicrobiana "in vitro" de extrato alcóolico de própolis. Ciência Rural, Santa Maria, v.34, n.1, p.159-163, 2004.

VIEIRA, G. H. C.; DARDANI, P.; ANDRADE, W. P. Efeito fungicida de produtos alternativos no controle de oídio em pepineiro. Revista Omnia Exatas, v. 2, n. 2, p. 45-49, 2009.

VIEIRA, G. H. da C.; DARDANI, P.; ANDRADE, W. da P.; BARBOSA, C. A. F. 044-Efeitos do extrato de própolis sobre a qualidade sanitária e fisiológica de sementes de feijão. Resumos do III Seminário de Agroecologia de MS. Cadernos de Agroecologia, v. 15, n. 1, 2010. Disponível em: <http://www.abaagroecologia.org.br/revistas/index.php/cad/ article/view/10170/6843>. Acesso em: 27 nov. 2016. 